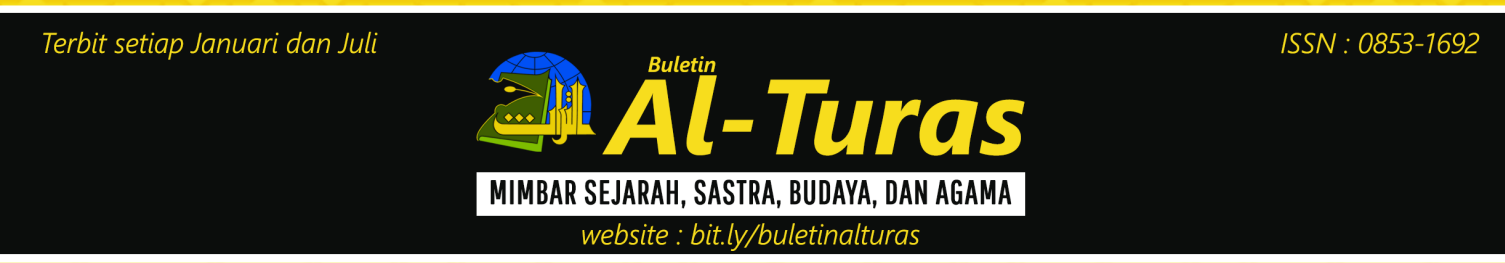

\title{
Puisi Arab Bersajak Karya Zaini-Solo; Kajian Paedagogik Islam-Modern dalam Manuskrip Nusantara ${ }^{1}$
}

Iin Suryaningsih ${ }^{2}$

\section{Abstract}

The presence of various modern Paedagogical currents carried by the Psychologists and observers of Western education, has made a new mapping in the study of modern education in Indonesia. Indeed the study has been popular since the early 20th century AD evidenced by one of the manuscripts entitled Mir'ätu Afkār al-Rijāl Nadzm Ta'līm al-Muta'līm by a scholar from Solo-Indonesia. This study proves that the content of modern Paedagogical study by a scholar in Indonesia looks very specific and holistic. The method used is a method of philology that includes textual criticism in manuscripts. This method will also capture the superiority of the study of Archipelago Paedagogical written with Arabic script. The results of this study that the study of Contemporary modernPaedagogical can be clearly found in the traces of the history of the past in the archipelago of Manuscript.

Keywords : Contemporary Paedagogical, Mir'ātu Afkār al-Rijāl, Arabic Poetry, Archipelago’s Manuscript

\section{Abstrak}

Hadirnya berbagai aliran Pendidikan Modern yang diusung oleh para Psikolog dan pemerhati Pendidikan Barat, telah membuat pemetaan baru dalam kajian ilmu Pendidikan Modern di Indonesia. Sejatinya kajian ini sudah populer sejak awal abad 20 Masehi yang dibuktikan dengan hadirnya salah satu manuskrip berjudul Mir'ātu Afkār al-Rijāl Nadzm Ta'līm al-Muta'lìm karya seorang cendikia asal Solo-indonesia. Penelitian ini bertujuan untuk membuktikan bahwa muatan kajian Paedagogik yang ada dalam karya cendikia asal Solo- Indonesia ini terlihat sangat spesifik dan holistik, mengungguli kajian Pendidikan Modern yang dibangun oleh generasi masa kini. Metode yang digunakan adalah metode filologi yang mencakup kritik teks pada manuskrip. Metode ini juga akan memotret keunggulan kajian Paedagogik Nusantara yang ditulis dengan skrip Arab. Hasil penelitian ini bahwa kajian Paedagogik Islam Modern secara nyata dapat kita temukan dalam jejak sejarah keilmuan masa lalu berupa Manuskrip.

Kata Kunci : Paedagogik Modern, Mir'ātu Afkār al-Rijāl, Puisi Arab bersajak, Manuskrip Nusantara

\footnotetext{
${ }^{1}$ Substansi dari deskripsi naskah dan konten secara umum teks pada manuskrip "Mir'āt afkār al-Rijal-Nadzm ta'lim al-Muta'lim" yang menjadi data utama penelitian ini, pernah disampaikan dalam tulisan sebelumnya yang dalam masa persiapan terbit di Jurnal Resia,Vol 1, No.1 UIN Jakarta, namun berbeda pada focus kajian diantara keduanya, khususnya pada pengambilan data specifik seperti penggalan bait yang dijadikan bukti kajian.

${ }^{2}$ Sastra Arab, Fakultas Ilmu Pengetahuan Budaya Universitas Al-Azhar Indonesia, Jakarta, email : iin.suryaningsih@uai.ac.id / qonitasalwaazkiya@gmail.com
} 


\section{A. Pendahuluan}

Penelitian berbasis manuskrip akan memperkenalkan kepada kita jejak sejarah dan budaya lokal tertentu yang sangat terkait dengan munculnya ilmu pengetahuan yang memiliki kultur lokal. Penelitian-penelitian yang terfokus pada data berupa manuskrip dari berbagai disiplin ilmu, telah membuktikan bahwa khazanah keilmuan yang dibawa oleh manuskrip sangatlah beragam dan potensial untuk diangkat pada pembahasan masa kini $^{3}$. Manuskrip Nusantara umumnya ditulis menggunakan aksara tradisional dan bahasa lokal daerah tertentu, dan aksara seperti ini yang sudah banyak ditinggalkan oleh type masyarakat masa kini karena satu dan beberapa sebab, diantaranya karena kesulitan dalam membaca isinya. Salah satu unsur dari kebudayaan adalah bahasa, dan dalam manuskrip tertulis bentuk bahasa yang digunakan pada zaman itu. Di dalamnya memuat pesan yang sangat berhubungan dengan filsafat hidup sebuah komunitas tertentu pada masanya ${ }^{4}$

Salah satu bukti karya sastra paedagogi Islam berupa nadzm yang sangat nyata diadopsi dari keilmuan Islam Arab oleh cendikia asal SoloIndonesia tahun $1934 \mathrm{M}$ adalah manuskrip berjudul Mir'ātu Afkār alRijāl Nadzm Ta'lìm al-Muta'lìm yang menjadi data penelitian pada artikel ini. Manuskrip ini ditulis dengan sistematika puisi bersajak, sebuah komentar dari

${ }^{3} \mathrm{~A}$ Iswanto - Al-Qalam and undefined 2016, 'Kecenderungan Kajian Manuskrip Keislaman Di Uin Syarif Hidayatullah Jakarta', Jurnalalqalam.or.Id $<\mathrm{http}$ //jurnalalqalam.or.id/ index.php/Alqalam/article/view/202> [accessed 28 July 2018].

${ }^{4}$ Tedi Permadi and others, 'Naskah Nusantara Dan Berbagai Aspek Yang Menyertainya' (Artikel. http://www. file. upi. edu. Diakses pada Sabtu, 2017)
( $m a t n$ ) buku yang ditulis oleh pengarang dari rentang masa dan latar belakang yang berbeda. Adalah Tajuddīn Nu'man ibn Ibrāhim al-Khalīl al-Zarnūji (570 $\mathrm{H})$, salah seorang pengarang kenamaan Zarand -salah satu daerah di wilayah Persia yang pernah menjadi ibu kota Sidjistan yang terletak disebelah selatan Herat- di bidang ilmu paedagogi dan kajian keislaman.

Sebuah pernyataan tegas yang disampaikan oleh Dr. Khalid ibn Hamid al-Hazimi ${ }^{5}$ bahwa banyaknya buku hasil pemikiran cendikia Arab muslim terdahulu tentang pendidikan Islam, adalah bukti jelas bahwa kajian ini sudah menjadi fokus pembahasan yang di anggap penting dalam Islam sejak beberapa abad lamanya. Para cendikia muslim sama sekali tidak meninggalkan celah sedikitpun tentang pembahasan pendidikan Islam sampai muncul anggapan bahwa pembahasan pendidikan merupakan kajian yang berasal dari Barat dan mereka mengambilnya dari para pembesar Yunani. Tentu butuh analisis panjang untuk mencermati dugaan tersebut, dan salah satu upaya kita sebagai generasi muslim masa depan adalah perlunya kembali pada konsep awal bagaimana Islam meletakkan kajian pendidikan Islam di awal sejarah agar kita mengetahui perkembangan yang telah dilakukan oleh konsep tersebut dengan kombinasi dari konsep pendidikan yang datang setelahnya.

\section{B. Pembahasan}

\section{Paradigma dalam Paedagogi;}

\section{Sebuah Landasan Normatif Agama dan Teoretis Modern}

${ }^{5}$ al-Hazimi, Hamid, Khalid, Dr. Ushul al-Tarbiyah al-Islamiyah, Dar 'alam al-Kutub- Fihrisah, Maktabah al-Malik Fahd al-Wathaniyyah$1420 \mathrm{H} / 2000 \mathrm{M}$ 
Pembahasan pendidikan Islam dibangun atas nilai-nilai normatif religi, namun tetap memperhatikan perkembangan pemaknaan landasan yang berupa filosofis, psikologis, dan sosiologis yang nyatanya saling berkaitan satu sama lain. ${ }^{6}$ Sebut saja idealisme, realisme, pragmatisme, eksistensialisme; merupakan paradigma filosofis yang mendasar ${ }^{7}$. Karya dari konsep dibidang tersebut fokus pada pendalaman metode praktis dalam mendidik, salah satunya mengusung metode Sandeson, Mason dan Montessori, disempurnakan dengan pijakan konsep Aristoles, Socrates, Plato, Ibnu Sina, al-Farabi, John locke dan Dewey. ${ }^{8}$

Kepribadian muslim terbentuk oleh pendidikan Islam, yang akan mengarahkan pada terjadinya sebuah perubahan sikap dan tingkah laku peserta didik sesuai dengan petunjuk ajaran Islam itu sendiri untuk membentuk manusia sempurna atau manusia paripurna. Pendidikan yang didasarkan pada Islamic Spirituality

${ }^{6} \mathrm{Dr}$, Nur'aini ahmad, M.Hum, Pendidikan Islam Humanis; Kajian pemikiran A.Malik Fadjar, Onglam books, Cet.Pertama 2017, hal 39

${ }^{7}$ William F. O'neil, Ideology-Ideologi Pendidikan; terj. Omi Intan Naomi (Yogyakarta, Pustaka Pelajar, 2001) hal.73

${ }^{8}$ Hal 10-1; John Dewey (1859-1952) adalah seorang Profesor di Universitas Chicago dan Colombia (Amerika), teori Dewey tentang sekolah adalah "Progressivim" yang lebih menekankan pada anak didik dan minatnya daripada mata pelajarannya sendiri. Maka muncul lah "Child Centered Curiculum" dan "Child Centered School". Progresivisme mempersiapkan anak masa kini di banding masa depan yang belum jelas, sebagaimana yang di ungkapkan Dewey dalam bukunya " $M y$ Paedagogical Creed", bahwa pendidikan adalah proses dari kehidupan dan bukan persiapan masa yang akan datang. Aplikasi ide Dewey, anak-anak banyak berpartisipasi dalam kegiatan fisik baru peminatan. and wisdom-based pedagogy, akan membangun prinsip komprehensif, integratif, keseimbangan, ketuhanan, kasih sayang, dan keteladanan, demikian makna dari paparan Prof. H. Furqon, Ph.D dalam The 1st UPI International Conference On Islamic Education, FPIPS UPI, Bandung, ( $\left(\cdot 17 / 9 / \Upsilon^{\top} \tau\right)$.

Adalah Al-Syaibāni yang menunjukkan bahwa reflektif akar pemikirannya berasal dari agama berupa al-qur'an dan al-hadis; menurutnya faktor psikologis dapat dijadikan dasar untuk menentukan semua aspek dalam pembelajaran yang meliputi tujuan, kurikulum, silabus, metode, sarana dan lainnya. ${ }^{9}$ Salah satu pembuktian keterkaitan landasan yang berupa normatif dengan hakikat yang nyata berdasarkan sosiologis adalah pada anjuran Islam terhadap kompetensi Paedagogik bagi para pendidik berupa nilai-nilai sosial yang melingkupinya dan kemampuan-kemampuan tersebut sudah dicontohkan sejak masa Rasullah SAW, sekaligus menunjukkan bahwa kompetensi yang mendasar dari paedagogik sudah diatur dan diperhatikan oleh konsep pengajaran Islam, sebagaimana beberapa dalil agama yang menjelaskan hal tersebut adalah sebagai berikut :

\section{a. Landasan Kependidikan}

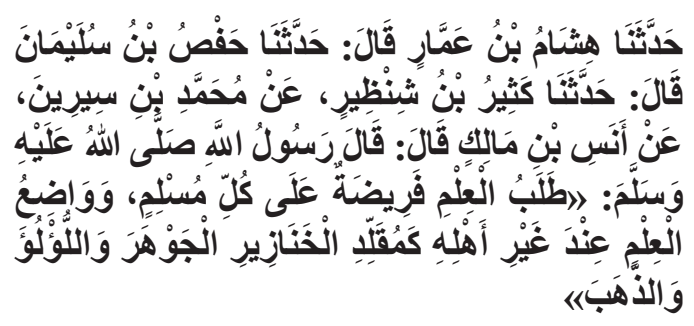

...Anas ibn Malik ra ia berkata : Rasullah SAW telah bersabda "Mencari imu itu wajib hukumnya kepada seluruh ${ }^{9}$ Al-Syaibāni, Muhammad 'Umar al-Taumi, Falsafah al-Tarbiyyah al-Islāmiyyah, Tripoli: al-Mansya'ah al- 'ৈ̆mmah li al-Nasyr wa alTauzī' wa al-I'lām 1985, hal. 8 
muslim. Dan meletakkan ilmu bukan pada ahlinya seperti mengalungi babi dengan permata, mutiara dan emas". (HR. Ibnu Majah; 17:224).

Secara tegas, pernyataan rasulullah SAW ini telah menjadi acuan dalam memaknai keutamaan pendidikan yang harus ditempuh oleh kita sebagai muslim tanpa terkecuali, laki-laki atau perempuan. Gambaran yang diberikan selanjutnya adalah merupakan gambaran bagi manusia yang memberikan amanah ilmu kepada yang bukan sepantasnya, seperti memberikan kalung emas dan perak kepada seekor babi.

\section{b. Tuntutan Kesepahaman antar Pendidik dengan Audiensnya}

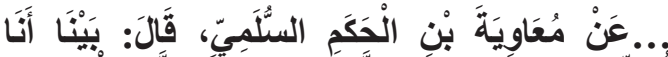

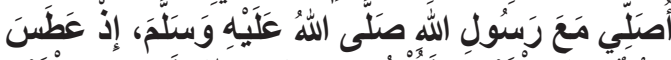

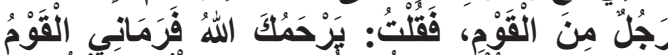

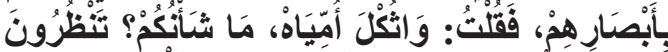

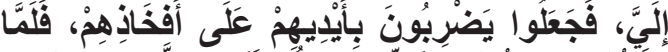

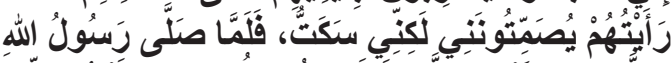

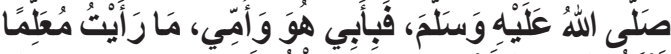

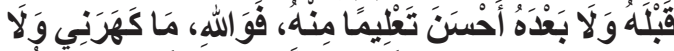

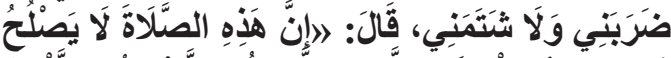

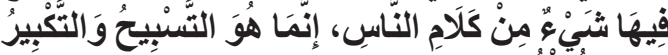

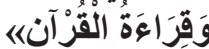

...dari Muāwiyah ibn al-Hakam alSulamiyyu, ...seorang lelaki tadi, dia berkata: Sesungguhnya demi ayahku dan ibuku, tidak pernah aku melihat seorang pengajar pun sebelumnya (Rasullah SAW) ataupun sesudah-nya yang lebih baik mengajar darinya. Dan demi Allah, ia tak pernah membenciku, tidak pula pernah memukulku atau mencaciku. Rasulullah SAW kemudian berkata : "Sesunguhnya dalam shalat tidak layak sedikitpun pembicaraan. kecuali hanya tasbih, takbir dan membaca alQur'an”. (HR.Muslim735:33)

Kronologis dari hadis tersebut menjelaskan kepada kita bahwa dalam proses pembelajaran yang terbangun sangat penting memperhatikan kesepemahaman antara dua belah pihak, yaitu pembelajar dan pengajarnya. Perilaku edukatif yang dicontohkan di atas adalah perilaku yang muncul dari diri rasulullah SAW sejak berabad lamanya. Pembuktian ini menjadi semakin nyata bahwa kearifan budi dalam jiwa pendidik yang dicontohkan oleh beliau merupakan keunggulan arah pendidikan Islam dalam memperhatikan teknis sebuah pembelajaran.

\section{c. Pengembangan Kurikulum atau Silabus.}

$$
\begin{aligned}
& \text { قال علي رضي الله عنه : علموا أولاد كم فإنّهم.... }
\end{aligned}
$$

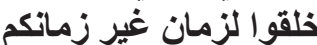

Ali ibn Abi Thalib berkata: "Ajarkanlah anak-anak kalian maka sesungguhnya mereka diciptakan untuk suatu zaman yang bukan zaman kalian" 10

Pendidikan perlu menjadi bekal demi kesiapan manusia untuk memahami keberagaman manifestasi nilai-nilai dalam peri kehidupannya sebagai anggota masyarakat. Peserta didik harus diperkenalkan ke berbagai bidang. Perkenalan itu akhirnya membuka perspektif bagi seseorang untuk membuat pilihan. Pandangan holistik dalam pendidikan Islam ${ }^{11}$ adalah pendidikan bermula dari prinsip tauhîd (keutuhan dan keterpusatan pada Tuhan). Hal inilah yang menjadi dasar pijakan dalam pandangan terhadap pendidikan. Prinsip tauhîd mencakup konsep filosofis maupun metodologis yang terstruktur dan koheren terhadap pemahaman kita terhadap dunia dan seluruh aspek kehidupan.

Dalam beberapa karya

${ }^{10}$ A. Zakaria, Zakaria. A (2003) Jami'ul Bayan fi Ulumul Qur'an. Garut : Ibn Azka. 2003: 191

${ }^{11} \mathrm{M}$. Zainuddin, 'Paradigma Pendidikan Islam Holistik', ULUMUNA, 15.1 (2011), $73<$ https:// doi.org/10.20414/ujis.v15i1.210>. 
paedagogi termasuk di dalamnya adalah ulama Nusantara, yaitu : "Ta'lîm alMuta'allim" karangan al-Zarnûjî, "alRisâlah al-Mufashshalah li Ahwâl alMuta'allimîn" karangan Abû al-Hasan al-Qâbisî, "Tadzkirah al-Sâmi' wa alMutakallim" karangan Ibn Jamâ'ah, "al-Jâmi' li Akhlâq al-Râwî wa Âdâb al-Sâmi", karangan al-Khatîb alBaghdâdî, juga kitab "Âdâb al-'Âlim wa al-Muta'allim dan al-Nûr al-Mubîn fì Mahabbah Sayyid al-Mursalîn" karangan KH. Hasyim Asy'ari ${ }^{12}$

Paradigma menurut Maslow manusia yang dapat mengaktualisasikan dirinya akan memiliki banyak puncak dari pengalamannya dalam hidup. Ia mengasumsikan bahwa manusia memiliki esensi biologis, karenanya pencarian jati diri menghadirkan tekanan yang nantinya mengindikasikan bahwa seseorang adalah bagian dari alam sebagaimana unique being. Karenanya dalam dunia pendidikan, teori Maslow yang berkaitan dengan motivasi menjadi referensi bagipara guru untuk mendeteksi berbagai persoalan kecenderungan motivasi rendah yang dialami peserta didik dalam proses pembelajaran. ${ }^{13}$ Guru tidak diperkenankan menghakimi peserta didik sebelum mempelajari kemungkinan terdapatnya proses tidak terpenuhinya kebutuhan anak yang berada di level kebutuhan untuk tahu dan mengerti. Seperti kemungkinan terdapatnya masalah keluarga yang membuatnya menjadi ketakutan, tidak tenang, depresi dan cemas, atau karena

${ }^{12}$ Iin Suryaningsih, 'Iin Suryaningsih, Shürat Al-Adab Al-Insāni';, 1.1 (2018), 1-19.

${ }^{13}$ MZ Ismail, MK Othman - Jurnal Penyelidikan Dedikasi, and undefined 2018, 'Amalan Pedagogi Abad Ke-21 Dalam Kalangan Guru Pelatih Program Ijazah Sarjana Muda Perguruan (Pismp) Pendidikan Islam DI', Ipgmipoh.Edu. My <http://www.ipgmipoh.edu.my/journal/index.php/dedikasi/article/view/70> [accessed 19 July 2018]; Zainuddin. terdapat masalah bagi pemenuhan kebutuhan fisik seperti terganggunya jadwal tidur akibat sesuatu hal.

Dalam Paedagogi dinilai merujuk pada penggunaan yang tepat dalam strategi mengajar. Sehubungan dengan strategi mengajar itu, filosofi mengajar diterapkan dan sangat dipengaruhi oleh latar belakang pengetahuan dan pengalamannya, situasi pribadi, lingkungan, serta tujuan pembelajaran yang dirumuskan oleh peserta didik dan pendidik ${ }^{14}$ Salah satu contohnya adalah aliran pemikiran Socrates. Sumbangsih Socrates yang terpenting bagi pemikiran Barat adalah metode penyelidikannya, yang dikenal sebagai metode elenchos, yang banyak diterapkan untuk menguji konsep moral yang mendasar dan ini sangat erat kaitannya dengan aspek psikologis peserta didik. Karena itu Socrates dikenal sebagai bapak dan sumber etika atau filsafat moral dan umum. Kata yang berhubungan dengan paedagogi dan atau pendidikan, sekarang digunakan untuk merujuk pada keseluruhan konteks pembelajaran, belajar, dan berbagai kegiatan yang berhubungan dengan hal tersebut.

Prinsip pendidikan modern
menurut cara pandang Rogers ${ }^{15}$ bahwa peserta didik belajar hal-hal yang bermakna bagi dirinya, dapat mengorganisasikan bahan dan ide sebagai bagian dari pembelajaran yang memiliki makna, dan belajar bermakna merupakan pembelajaran proses dan ini sejalan dengan konsep pendidikan

\footnotetext{
${ }^{14}$ Pauline W U Chinn, 'Developing Teachers' Place-Based and Culture-Based Paedagogical Content Knowledge and Agency', in Second International Handbook of Science Education (Springer, 2012), pp. 323-34.

${ }^{15}$ Iin Suryaningsih; Resia,vol 1, No.1 2018, Zainuddin, M. (2011). Paradigma Pendidikan Islam Holistik. Ulumuna, 15(1), 73. https://doi. org/10.20414/ujis.v15i1.210
} 
karakter yang di usung sebagai kearifan dari keaneragaman nilai dan budaya kehidupan bermasyarakat dan upaya seseorang membuka diri untuk menjalani kehidupan bersama dengan melihat realitas plural yang terjadi. Oleh karena itu selayaknya pendidikan harus diletakan pada posisi yang tepat. Pembelajaran diharapkan memenuhi kaidah prinsip humanistik dengan mengedepankan proses yang memberikan kesempatan terwujudnya pembelajaran bermakna.

\section{Filologi; Asumsi Memberlakukan Kritik pada Teks}

Sebuah penelitian filologis berawal dari asumsi dasar yang nampak dalam karakteristik naskah-naskah lama, di dalamnya mengandung ide pikiran, perasaan, tradisi, adat-istiadat, dan budaya yang pernah ada pada masa tertentu, dan dianggap sangat relevan jika diterapkan pada kondisi kekinian dan masa depan ${ }^{16}$. Di sisi lain, perlu kita ingat kembali bahwa nilai-nilai berharga yang tersimpan dalam naskahnaskah tersebut, tertulis dalam media yang sangat rentan bertahan di beberapa situasi dan kondisi, dimakan usia. Sebut saja kertas, dluwang, daun lontar, atau bambu, dengan tinta di atasnya. Jika melihat tradisi penyalinannya, dalam hampir semua naskah yang kita jumpai bukan merupakan naskah asli yang ditulis langsung oleh pengarangnya otograf) ${ }^{17}$ melainkan hasil salinan yang

\footnotetext{
${ }^{16}$ Ma'mun, Titin Nurhayati; Atikan, T. M.-, \& 2016, undefined. (n.d.). Lektur Agama Islam: Konsep dan Penanganan Naskah Klasik Nusantara. Mindamas-Journals. Com. Retrieved from http://mindamas-journals.com/index.php/ atikan/article/view/107

${ }^{17}$ Oman Fathurahman - Filologi dan Penelitian Teks-Teks Keagamaan (substansi makalah ini pernah disampaikan Workshop Pengembangan Agenda Riset, yang diselenggarakan oleh Local Project Implementing Unit (LPIU) UIN Syarif
}

sering kali dilakukan secara berulangulang oleh murid, murid dari muridnya bahkan kerabat dan orang penyalin yang tidak semasa lagi dengan penulisnya $i^{18}{ }^{18}$. Tradisi penulisan teks seperti Hidayatullah Jakarta, di Wisma YPI, Ciawi Bogor, 27 Maret 2000)

${ }^{18}$ I Suryaningsih, H Hendrawanto - JURNAL Al-AZHAR INDONESIA, and universitas AlAzhar Indonesia 2018, 'Ilmu Balaghah: Tasybih Dalam Manuskrip "Syarh F̄̄ Bayān Al-Majāz Wa Al-Tasybīh Wa Al-Kināyah",, Jurnal. Uai.Ac.Id, 4 (2018) <http://jurnal.uai.ac.id/ index.php/SH/article/view/245> [accessed 29 July 2018].comes from exchanges of science scholars who studied the archipelago to Mecca and Medina and then returned to carrying the Arabic script, then the script is a learned society scientific studies in Indonesia.Expression of tasybih popular used by the Arabic poets since the golden age of literature in history etched in the period of Ignorance. The language style of tasybih is an attempt to express something with speakers equate the things he meant by something else that has similarities to the effects and consequences. Bayan science in language is the explanation, disclosure and description. While the term science in bayan means basic or rule that describes the desire to achieve the one meaning with various styles of language. The method used in this research is divided into two stages, the first method is Philology, used for reading and analyzing texts in manuscript precisely, and second: descriptive methodswith objective approach, amethod which will focus only on a single text, analysis and elaborate on the contents of the text thoroughly and clearly. This research is expected to complement previous studies as well as broaden insights into the corpus of knowledge that is contained in the manuscript. Thus, the analysis of the scientific information contained in the manuscript could be developed and examined in more details.","author":[\{“dropping-pa rticle":",,"family":"Suryaningsih","give n":"I","non-dropping-particle":",,"parsenames":false,"suffix":"”, $\},$ “dropping-pa rticle":",,"family":"INDONESIA","g iven":"H Hendrawanto - JURNAL AlAZHAR","non-dropping-particle":",,"parsenames":false,"suffix":", \}, “dropping-par ticle":",",family":"2018","given":"univer sitas Al-Azhar Indonesia","non-droppingparticle":",",parse-names":false,"suf fix":", \} ],"container-title":"jurnal.uai. 
inilah yang akhirnya menimbulkan apa varian (teks- teks salinan); sangat rentan terhadap perubahan, baik yang disengaja maupun tidak, sehingga tidak jarang teks yang kita jumpai butuh penyelidikan kembali otentisitasnya melalui tahapan yang dinamakan metode filologi.

Berikut secara singkat adalah tahapan yang dilakukan dalam kajian filologi: (1) Inventarisasi Naskah; salah satu tujuan inventarisasi naskah yang sangat penting adalah untuk mendaftarkan semua naskah yang akan ditelitidariberbagaitempatpenyimpanan naskah $^{19}$ seperti perpustakaan, museum, bahkan pada koleksi perorangan. Mendata keberadaan naskah penelitian ini perlu ketelitian karena seringkali sebuah teks terdapat dalam beberapa salinan, sehingga kekurangan teks yang satu bisa ditutupi oleh teks lainnya. (2) Pemerian Naskah; Tahap penelitian berikutnya adalah memetakan semua naskah yang bertujuan agar keadaan naskah diketahui secara detail dan valid secara fisik maupun kandungan isinya. Dengan pemerian naskah ini peneliti juga akan dapat melakukan perbandingan naskah, dan akhirnya menentukan ac.id","id":"ITEM-1","issued": \{“dateparts":[[“2018”]]\},"title":"Ilmu Balaghah: Tasybih dalam Manuskrip "Syarh Fī Bayān al-Majāz wa al-Tasybīh wa alKināyah",,"type":"article-journal","volum e":"4"\},"uris":["http://www.mendeley.com/ documents/?uuid=76d59f75-d94f-3090-833574272e82a3c8"]\}],"mendeley":\{“formatted Citation":"I Suryaningsih, H Hendrawanto - JURNAL Al-AZHAR INDONESIA, and universitas Al-Azhar Indonesia 2018, 'Ilmu Balaghah: Tasybih Dalam Manuskrip "Syarh Fī Bayān Al-Majāz Wa Al-Tasybīh Wa AlKināyah"', <i>Jurnal.Uai.Ac.Id</i>, 4 (2018

19 Iin Suryaningsih.-P. K., \& 2016, U. (2016). Sastra Islam Dalam Manuskrip (Kajian Teks Ber-Aksara Jawi Sebagai Salah Satu Bahan Ajar Mahasiswa. In prosiding.arab-um.com (Vol. 1, p. 541). Malang: UM. Retrieved from http://prosiding.arab-um.com/index.php/konasbara/article/viewFile/100/93 naskah mana yang akan dijadikan landasan pengkajian tertentu ${ }^{20}$.

Pemerian naskah mencakup data-data pokok berikut, diantaranya : kode dan nomor naskah, judul, pengarang, penyalin, tahun penyalinan, tempat penyimpanan, asal naskah, pemilik, media tulis naskah, kondisi fisik naskah dll. ${ }^{21}$ (3) Kritik terhadap Teks; dalam konteks filologi, kritik teks bertujuan untuk mendapatkan bentuk teks yang asli, teks yang otentik, yang ditulis oleh pengarang sendiri (otograf). Target seperti ini sebenarnya jarang sekali terpenuhi, oleh karenanya, sebuah kritik teks paling tidak ditujukan untuk dapat mencapai ketetapan teks (constitutio textus), yaitu teks tersebut bisa sedekat mungkin dengan aslinya, bersih dari penyimpangan- penyimpangan atau kekeliruan, sehingga ia bisa dianggap sebagai tipe mula atau naskah arketip (archetypus). ${ }^{22}$

${ }^{20}$ lihat : Baried, Siti Baroroh. 1983, Oman Fathurahman, Filologi dan Penelitian TeksTeks Keagamaan. Sites.Google.Com. Retrieved from https://sites.google.com/site/omanwae/ FilologidanPenelitianTeksKeagamaan.pdf

${ }^{21} \mathrm{O}$ Fathurahman - dalam Seminar Lokal Project Implementing Unit and Undefined 2003, 'Filologi Dan Penelitian TeksTeks Keagamaan', Sites.Google.Com $<$ https://sites.google.com/site/omanwae/ FilologidanPenelitianTeksKeagamaan.pdf> [accessed 29 July 2018].

22 Suryaningsih, INDONESIA, and 2018. comes from exchanges of science scholars who studied the archipelago to Mecca and Medina and then returned to carrying the Arabic script, then the script is a learned society scientific studies in Indonesia.Expression of tasybih popular used by the Arabic poets since the golden age of literature in history etched in the period of Ignorance. The language style of tasybih is an attempt to express something with speakers equate the things he meant by something else that has similarities to the effects and consequences. Bayan science in language is the explanation, disclosure and description. While the term science in bayan means basic or rule that describes the desire to achieve the one meaning with various styles of language. The method used in this research 


\section{Karya tradisi Intelektual Cendikia Nusantara}

Dalam tradisi intelektual Islam Nusantara, ${ }^{23}$ pengertian teks dibedakan menjadi matan (matn), komentar (syarh), dan penjelasan (hasyiyah). Matan adalah teks utama yang menjadi landasan bagi setiap pengarang. Umumnya, ditulis bukan oleh pengarang matan itu, sedangkan syarh

is divided into two stages, the first method is Philology, used for reading and analyzing texts in manuscript precisely, and second: descriptive methodswith objective approach, amethod which will focus only on a single text, analysis and elaborate on the contents of the text thoroughly and clearly. This research is expected to complement previous studies as well as broaden insights into the corpus of knowledge that is contained in the manuscript. Thus, the analysis of the scientific information contained in the manuscript could be developed and examined in more details.","author":[ [“dropping-particle":","," family":"Suryaningsih","given":"I",,non-dropping-particle":",",parse-names":false,"suffix":""’\},\{“dropping-particle":"’,,"family":"'INDONESIA","given":"H Hendrawanto - JURNAL Al-AZHAR","non-dropping-particle":",',"parse-names":false,"suffix":"", \}, \{“dropping-particle":",,",family":"2018","given":"universitas Al-Azhar Indonesia","non-dropping-particle":"',",parse-names":false,"suffix":""\} ],"container-title":"jurnal.uai.ac.id","id":"ITEM-1","issued": \{“date-parts":[[“2018”]]\},”title":.'Ilmu Balaghah: Tasybih dalam Manuskrip "SyarhF̄̄Bayānal-Majāz wa al-Tasybīh wa al-Kināyah",",type":"article-journal","volume":"4"\},"uris":["http:// www.mendeley.com/documents/?uuid=76d59f 75-d94f-3090-8335-74272e82a3c8"']\}],"mendeley": \{“formattedCitation":"Suryaningsih, INDONESIA, and 2018.","plainTextFormattedCitation":"Suryaningsih, INDONESIA, and 2018.","previouslyFormattedCitation":"Suryaningsih, INDONESIA, and 2018."',",properties":\{“noteIndex":23\},"schema":"https:// github.com/citation-style-language/schema/ raw/master/csl-citation.json"\}

${ }^{23} \mathrm{KM}$ Luthfi - IBDA:Metodologi Dan Kontekstualisasi Filologi Dalam Kajian Teksteks Islam Nusantara and Institut Pesantren Mathali'ul Falah 2016, 'Metodologi Dan Kontekstualisasi Filologi Dalam Kajian Teks-Teks Islam Nusantara', Ejournal. Iainpurwokerto.Ac.Id, 14 (2016), $114<\mathrm{http}: / /$ ejournal.iainpurwokerto.ac.id/index.php/ibda/ article/view/523> [accessed 28 July 2018]. dan hasyiah ditulis untuk memberikan penjelasan terhadap matn. Karya klasik Nusantara yang terdiri dari matn syarh hasyiyah sangatlah banyak, sehingga kajian filologis naskah keislaman Nusantara klasik tidak hanya dibatasi pada pengertian matn syarh hasyiyah teks saja, melainkan diperkaya dengan ketiga istilah lainnya. sebagaimana berkembang pula tradisi tulis narasi dan puisi. Banyak kitab matan yang berbentuk puisi, dibuatkan syarahnya berbentuk narasi. Banyak pula kitab narasi yang dibuatkan kitab baru berbentuk puisi. Al-Ajurumiyyah adalah kitab matan narasi untuk kajian tata bahasa Arab yang menjadi kajian utama santri pemula. Lepas Al-Ajurumiyyah, santri mengenal kitab 'Imrithi yang berbentuk nadzm atau puisi (Sunda = nadoman, Jawa $=$ nembang) yang merupakan puisi dari Al-Ajurumiyyah.

Tradisi ini tidak sekadar menjadi kajian, namun berkembang pula menjadi karya-karya baru para priyai dan santrisantri Indonesia khususnya di Pulau Jawa. Bila kita menengok madrasahmadrasah diniah di pedesaan kita akan menjumpai murid Madrasah Diniah mendapatkan pelajaran berbentuk $n a d z m$ dalam bahasa daerahnya. Orang Jawa dengan nadzm Jawa dan lain sebagainya, Nadzm tersebut adalah karya para priyai dan santri di Jawa ${ }^{24}$. Para santri kerap kali menuliskan namanya pada lembar pertama kitab yang mereka miliki. Pada lembaran-lembaran berikutnya, tak sekadar membubuhkan makna dari teks inti, tetapi mereka juga terkadang menuliskan hal-hal lain pada ruangruang kosong di setiap halamannya, keterangan dari kyainya, misalkan :

${ }^{24}$ Kabul Astuti, Aspek Tasawuf Dalam Manuskrip Beraksara Pegon: Kajian Atas Serat Munjiyat Karya Kyai Saleh Darat Dan Singir Parase Nabi Karya Anonim, $2014<$ http://eprints.ums. ac.id/38306/> [accessed 18 July 2018]. 
pada lembar terakhir, para santri akan mencatat titimangsa waktu dan tempat ia menyelesaikan kitab tersebut bersama kyainya itu.

Nadzm dan karya tulis tersebut tidak lepas dari nilai-nilai sastrawi ${ }^{25}$ bisa kita temukan bagaimana priyai itu membuat puisi bersajak. Bahkan dapat dicermati dalam berbagai momen tabligh, ceramah, dan tausiyyah, tradisi puisi bersajak menjadi bagian dari model dan gaya penyampaian para priyai. Dalam kajian sastra Arab, genre sastra tulis adalah puisi dan prosa. Puisi merupakan ungkapan yang terikat dengan pola rima (qafiyah) dan irama (bahr) tertentu (Hasyimi:1998). Definisi ini akhirnya memunculkan pembagian puisi berdasarkan kepatuhan pola tersebut, menjadi : al-syi'ru al-'Amūdi (puisi dengan pola kepatuhan rima dan iramanya), al-syi'ru al-hurr (puisi bebas, dengan kepatuhan pola rima dan iramanya yang sangat minimal), dan al-syi'ru al-Mantsur (puisi bebas tanpa kepatuhan pola sama sekali, bentuknya narasi seperti prosa). (Dhayf:1998). Pola inilah yang akan menjadi salah satu fokus peneliti dalam upaya menemukan penetrasi keilmuan Islam Arab di Jawa.

\section{Puisi Arab Bersajak; Keunggulan Kajian Paedagogi Islam dalam Manuskrip Nusantara}

\section{Deskripsi Naskah}

"Mir'āt Afkār al-Rijāl" di tulis oleh salah seorang ulama kenamaan Solo. Berdasarkan data yang tertulis di lembar utama naskah, kitab ini berjudul “Mir'āt afkēr al-Rijal-Nadzm ta'lim al-

\footnotetext{
${ }^{25} \mathrm{TN}$ Ma'mun and Lektur agama Islam; Konsep dan Penanganan Naskah Klasik Nusantara 2016, 'Lektur Agama Islam: Konsep Dan Penanganan Naskah Klasik Nusantara', Mindamas-Journals. Com, 1 (2011) <http://mindamas-journals.com/ index.php/atikan/article/view/107> [accessed 29 July 2018].
}

Muta'lim". Teks di tulis dengan bahasa Arab fusha (formal), dengan karakter puisi berpola dan memiliki konsistensi rima pada setiap bait nya, sesuai dengan kekhususan pada karakter puisi Arab masa klasik.

Sebagaimana diketahui gaya penulisan kitab klasik Arab pada umumnya, pengarang menuliskan muqaddimah yang panjang; di dalamnya menuliskan ungkapan pembuka dan rasa syukur serta memperkenalkan secara umum maksud tujuan dari karangannya itu. Maka demikianlah juga kitab ini, sepanjang bait pertama sampai bait ke delapan; penulisnya membuat rangkaian pendahuluan yang di awali dengan ucapan hamdalah, shalawat untuk nabi SAW dan para sahabat, lalu beliau menegaskan bahwa benar kitab ini adalah nadzm dari kitab ta'lim almuta'lim karya ulama Arab muslim bernama al-Zarnūji, namun kemudian ia memberinya nama dengan mir'āt afkāral-rijāl (mir' ātal-afkār:baris 1-7) ${ }^{26}$ merupakan kitab yang akan memberikan informasi tentang etika dan tata cara memahami ilmu. Teks ini berjumlah 272 bait, menerapkan metrum/bahr rojaz, aksara/skrip di tulis dengan huruf Arab formal/fusha, karangan ini selesai ditulis selama 10 hari $^{27}$, dan informasi ini diabadikan dalam penutup bait nadzm dengan ungkapan :

$$
\text { نظمتها في عشرة الأيام بقدرة المهيمن العلام }
$$

Jika ditulis menggunakan versi ilmu metrum Arab ('Arudh) maka terlihat dengan jelas penerapan ilmu ini

${ }^{26}$ Mir' āt Afkār al-Rijāl; Manuskrip karya ahmad Zaini - Solo, hal 1, baris 1-7

${ }^{27}$ Deskripsi naskah "Mir'āt Afkār al-Rijāl'ini pernah penulis sampaikan juga dalam sub pembahasan artikel pada Jurnal Resia (Review of Islam southeast Asia), Vol.1 No. 1, 2018 yang sedang dalam proses terbit, merupakan salah satu rintisan Jurnal fakultas Adab dan Humaniora UIN Jakarta 
dalam teks, adalah :

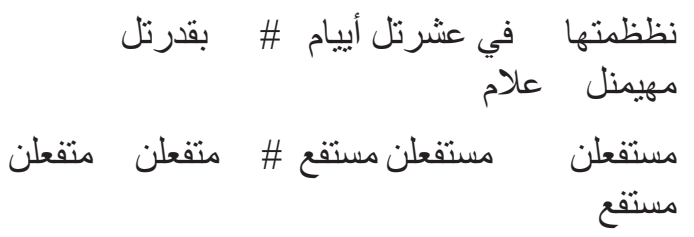

nadzamtuhā fi asyrati al-ayyāmi, bi qadri al-muhaymini al- 'alāmi

"saya membuat nadzam ini dalam "saya merangkai puisi ini dalam waktu sepuluh hari, dengan kekuatan yang Allah SWT berikan" (mir'āt al-afkār:baris 269)

\# Qafiyah (rima) yang digunakan dalam bait ini adalah qafiyah harf Mìm dengan bahr Rajaz

Kitab ini diverifikasi oleh seorang ulama Universitas Al-Azhar Cairo, beliau menjabat sebagai direktur pimpinan redaksi; bernama : Ahmad Sā'id 'Ăli, dengan penanggung jawab penerbitan ; Muhammad Amīn 'Imrān, dan direktur penerbitan : Rustam Mustafā al-Halabīy. ${ }^{28}$

Tema pembahasan dari kitab ini sepenuhnya mengikuti struktur tema pada kitab Ta'lìm al-Muta'lim fi Tharīqat al-Ta'allum karya Burhān al-Din al-Jarnūzi (w-593H), terdiri dari pendahuluan, dan 11 (sebelas) pembahasan. Hasil dari proses editing yang telah dilakukan terhadap manuskrip ini adalah teks yang sudah siap baca dilengkapi dengan tanda baca di beberapa kata yang di nilai sulit, versi tulisan ketik rapi dengan media modern yaitu komputer, diberi tanda nomor baris pada tiap 5 baris teks nya sebagai upaya memudahkan pembaca dalam mempelajari teks tersebut, diterbitkan

\footnotetext{
${ }^{28}$ Penulis sudah mendapatkan naskah ini berupa PDF yang siap unggah dan siap baca dengan kelengkapan tanda bacanya pada beberapa bagian kata yang dianggap sulit oleh umumnya pembaca.
}

oleh maktabah al-halabīy Cairo. ${ }^{29}$

Penulis menemukan manuskrip ini dalam bentuk kitab PDF yang ada pada koleksi pribadi salah seorang kolektor dan peneliti naskah Nusantara, dan telah menelusurinya secara ilmiah keberadaan dan asal usul teks, berkesimpulan bahwa teks ini belum pernah diteliti secara ilmiah kecuali deskripsi singkat/ulasan yang dilakukan oleh pemilik naskah ini. Berdasarkan hal tersebut, maka penulis sangat yakin untuk meneliti kitab ini dan menjadikan kitab ini sebagai sumber data artikel ilmiah yang akan mengangkat tema penting seputar pembuktian terhadap pengaruh paedagogi islam dan ilmu bahasa Arab di Nusantara.

\section{a. Karakter Puisi Arab; tinjauan ilmu Metrum arab ('Arüdh wa al-Qawāfī)}

Penulisan nadzam pada ilmu Paedagogi dalam bahasa Arab yang dihasilkan dari pemikiran cendikia Nusantara asal Solo ini memperlihatkan adanya proses adaptasi pola puisi Arab ke dalam puisi karya tokoh di Solo-Nusantara. Adaptasi pada tataran puitika tersebut dengan sendirinya juga menunjukkan respon pengarangnya terhadap kesusastraan yang berasal dari luar, yang tidak hanya mengambil atau menerima begitu saja, melainkan menyesuaikan secara kreatif dengan budayanya sendiri, yakni Solo-Jawa. ${ }^{30}$ Dengan demikian, penting bagi penulis untuk menggambarkan secara umum beberapa yang menjadi perhatian khusus untuk mengenal dan mempelajari karakter puisi Arab melalui pemetaan

\footnotetext{
${ }^{29}$ Iin Suryaningsih, Resia ,vol 1, No.1 2018

${ }^{30}$ Agus Iswanto; Peneliti Lektur dan Khazanah Keagamaan pada Balai Litbang Agama Semarang,Review Buku: Tradisi Islam, Tradisi Arab dan Tradisi Jawa: Membaca Karya dan Pemikiran K.H. Ahmad ar-Rifai Kalisalak, https:// Jurnallekturkeagamaan.kemenag.go
} 
pola dalam ilmu metrum atau yang biasa disebut dengan istilah ilmu 'Arüdh wa

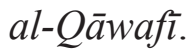

\section{Faedah Ilmu 'Arüdh}

Ilmu 'Arudh mempunyai banyak faedah, yang diantarnya adalah untuk membedakan antara pola tulisan puisi $=$ dengan Prosa. Alquran bukanlah kumpulan sya'ir-sya'ir Arab, meskipun Nampak beberapa pola kata yang tersusun dalam kaliamat di dalamnya memiliki susunan seindah syair. Banyak ulama yang berpendapat seperti Syekh Hanafi : "bahwasanya mempelajari sesuatu yang bisa membedakan antara Alquran dengan sya'ir hukumnya fardlu 'ain". Sebab hal itu bisa mencegah subordinasi dalam akidah. Di samping itu, dengan ilmu 'Arüdh kita juga bisa terhindar dari kerancauan satu pola bahr dengan yang lain, serta menjaga puisi dari perubahan. Dengan semua kelebihan itu, jelaslah bahwa ilmu 'Arudh memiliki faidah yang sangat besar.

Sasaran/objek ilmu ini adalah puisi Arab yang memiliki kekhususan pola dalam ritme, rima dan iramanya. Dengan mempelajari ilmu ini, para pengkaji sastra Arab akan mengetahui adanya pola tertentu dalam pembentukan puisi tersebut dan pola itu di adopsi dari generasi-generasi awal masyarakat Arab yaitu masa Jahiliyah. ${ }^{31}$

\section{Beberapa istilah yang perlu diketahui} dalam ilmu 'Arudh:

Wazan, yang dimaksud disini adalah kumpulan dari untaian nada yang harmonis bagi kalimat-kalimat yang tersusun dari satuan-satuan bunyi

\footnotetext{
${ }^{31}$ Substansi pembahasan ilmu 'Arudh dan faedahnya ini, penulis sampaikan dalam buku berjudul "Kajian Puisi dan Prosa Arab" yang sedang dalam proses layout dan cetak, diterbitkan oleh UAI Press
}

tertentu yang meliputi harakah (huruf hidup) dan sakanah (huruf mati) yang melahirkan taf'ilah-taf'ilah dan bahr syair.

Zihäf, adalah perubahan yang ditentukan oleh huruf yang keduanya sabab (sabab khofif / tsaqīl) secara muthlaq. Sedangkan zihaf tidak bisa masuk kepada huruf awal dan huruf ke tiga juga huruf ke enam dari juz tafaā' $i l$.

'Illah, pengertian 'illah dalam ilmu 'Arudh adalah perubahan yang terjadi pada sabab dan watad dari taf'ilah 'arudh dan taf'ilah dharab. 'illah sifatnya lazim, artinya apabila terjadi pada 'arudh dan dharab atau pada salah satunya maka semua bait harus mengikutinya.

Qafiyah, adalah sebuah ilmu yang membahas ujung kata di dalam bait syiir yang terdiri dari huruf akhir yang mati di ujung bait sampai dengan huruf hidup sebelum huruf mati.

Bait, menurut istilah dalam ilmu 'arudh Bait adalah suatu ungkapan sastra yang kata-katanya tersusun rapi untuk mengikuti not-not yang tersedia dalam taf'ilah-taf'ilah dan diakhiri dengan qafiyah.

$\boldsymbol{B a h r}$, adalah wazan (timbangan) tertentu yang dijadikan pola dalam menggubah syi' ir arab.

Berikut adalah ilustrasi beberapa istilah di atas seperti sabab dan watad dalam pembentukan taf'ilah:

\section{Maqtha' Arudhiy}

Penggalan suku kata dalam tiap pola (wazan) pada puisi Arab yang terdiri dari minimal 2 (dua) hiruf, sampai paling banyak terdiri dari 5 (lima) huruf. Dari beberapa pola yang terdapat dalam intonasi puisi Arab tersebut, berikut ini adalah diantaranya : 


\begin{tabular}{|c|c|c|c|}
\hline الأمثلة & تعريف كل قسم & الأقسام & الأنواع \\
\hline لُّم & متحاريك فساكن & خفيف & \multirow[t]{2}{*}{ السبب } \\
\hline أزي & متحركان & ثقيل & \\
\hline عُلَّى & فتحاكن & مجموع & \multirow[t]{2}{*}{ التوتد } \\
\hline ظُهز & متحركان $\quad$ بيثن & مفرعق & \\
\hline جَبَتُنْ & فُلائة متحركات & صغزى & \multirow[t]{2}{*}{ الفاصلة } \\
\hline سنتَكَّنَ & فَبنيعة متحركات & كبزى & \\
\hline
\end{tabular}

Tabel 1. Macam-macam Maqtha' Arudhy, klasifikasi dan contohnya

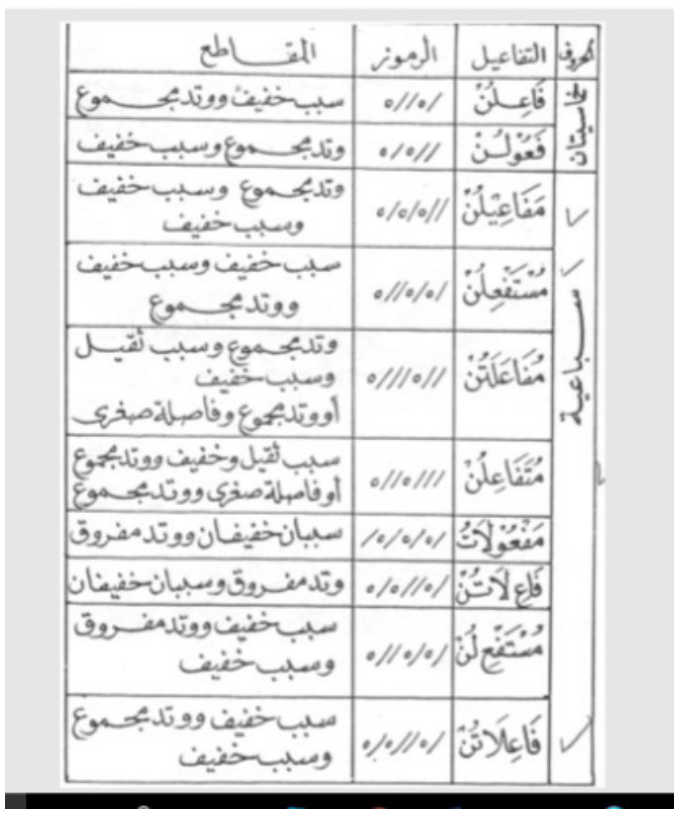

Table 2 Maqtha' Arudhy, Taf'ilah dan Rumuz (simbol cara penulisan tiap suku kata) ${ }^{32}$

Menurut Imam Kholil, jumlah bahr ada 15, sedangkan menurut imam Akhfasy jumlah bahar ada 16, dengan menambahkan satu bahar lagi, yakni bahar mutadarik.

Berikut adalah macam-macam bahr dalam 'Ilmu 'Arudh:

\section{Bahr Thawìl}

فعولن مفاعيلن فعولن Juz tafa 'ilnya adalah ${ }^{32}$ Chatibul Umam, al- 'Arüdh, 1992, hal.10
مفاعيلن \# فعولن مفاعيلن فعولن مفاعيلن

\section{Bahr Madìd}

Juz tafa 'ilnya adalah: فاعلاتن فاعلن فاعلاتن فاعلن \# فاعلاتن فاعلنفاعلاتن فاعلن

\section{Bahr Basith}

Juz tafa 'ilnya adalah: مستفعلن فاعلن مستفعلن فاعلن \# مستفعلن فاعلنمستفعلن فاعلن

\section{Bahr Wafir}

Juz tafa 'ilnya adalah: مفاعلتن مفاعلتن مفاعن مفا مفاعلتن \# مفاعلتن مفاعلتن مفاعلنن

\section{Bahr Kāmil}

Juz tafa 'ilnya adalah: متفاعلن متفاعلن متفاعلن \# متفاعلن متفاعلن متفاعلن : متن

\section{Bahr Hazj}

Juz tafa 'ilnya adalah: مفاعيلن مفاعيلن مفاعيل \# مفاعبلن مفاعيلن مفاعبلن : مفاعن

\section{Bahr Rajaz}

Juz tafa'ilnya adalah: مستفعلن مستفعلن مستفعلن \# مستفعلن مستفعلن مستفعلن

\section{Bahr Raml}

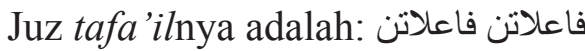
فاعلاتن \# فاعلاتن فاعلاتن فاعلاتن

\section{Bahr Sarī'}

Juz tafa'ilnya adalah: مستفعلن مستفعلن مفعو لات \# مستفعلن مستفعلن مفعو لات

\section{Bahr Khofif}

فاعلاتن مستفع لن:Juz tafa 'ilnya adalah فاعلاتن \# فاعلاتن مستفع لن فاعلاتن

\section{Bahr Mudhāri'}

مفاعبلن فاع لاتن:Juz tafa 'ilnya adalah مفاعيلن \# مفاعيلن فاع لاتن مفاعيلن

\section{Bahr Muqtadhab}

Juz tafa 'ilnya adalah: مفعو لات مستفعلن مستفعلن \# مفعو لات مستفعلن مستفعلن : مساi

\section{Bahr Mutaqārib}

Juz tafa'ilnya adalah: فعولن فعولن فعولن فولن فين فين فعولن \# فعولن فعولن فعولن فعولن 
Bentuk puisi Arab tradisional sejak masa pra-Islam sampai sekarang masih digunakan oleh para penyair. Bentuk ini adalah bentuk yang diperkenalkan oleh al-Khalīl al-Farīhidiy al-Basriy, salah seorang pelopor linguis Arab, yang menciptakan ilmu pola puisi yang disebut ilmu ‘arūd dan Qäfiyah.

Pola puisi dalam ilmu 'arudh ada 16 pola yang disebut bahr, yaitu 4 pola bermetrum delapan, 8 pola bermetrum enam, dan 4 pola bermetrum empat. Berikut adalah perincian bahr rajaz yang diterapkan dalam data penelitian ini :

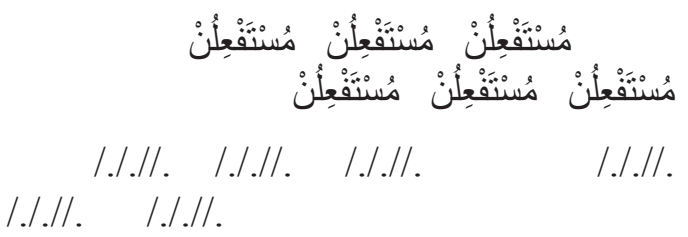

\section{Kajian terhadap Teks;}

Pembahasan pertama dalam kitab ini fokus pada kategorisasi ilmu, pengetahuan tentang kategori tersebut serta pengetahuan tentang para ahli di bidangnya. Pembahasan ini menjabarkan dengan rinci tentang kategori ilmu; yaitu mulai dari ilmu utama yang harus dipelajari seperti shalat, zakat, puasa dan haji, demikian juga hal nya ilmu jual beli yang akan memberikan pengetahuan kepada kita tentang penjagaan diri dari pemerolehan dari yang syubhat. Yang lebih menarik juga adalah, pengarang menyatakan bahwa semua ilmu itu mulia dan pantas untuk dipelajari dengan baik selama kegunaan ilmu tersebutpun untuk memuliakan makhluk hidup baik di bumi maupun di langit. Ungkapan ini terekam dalam bait nadzmnya sebagai berikut :

$$
\text { وكل علم شرف لا يخفى لأحد لفرق بينا يلفى }
$$

Jika ditulis menggunakan versi ilmu metrum Arab ('Arudh) maka terlihat dengan jelas penerapan ilmu ini dalam teks, adalah :

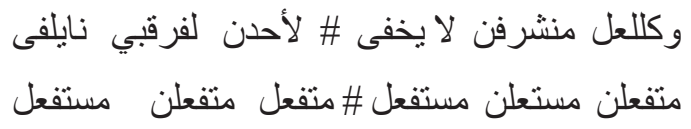

Wa kullu 'ilmin syarafun lā yakhfā, Li ahadin li farqi bainā yalfā

"...dan setiap ilmu adalah mulia, tidak ada yang hampa bagi kita manusia" (mir'āt al-afkār:baris 15)

Qafiyah (rima) yang digunakan\# dalam bait ini adalah qafiyah harf Alif maqsurah

Pelengkap materi yang sangat unggul dari pemahaman teks di atas adalah juga bahwa memuliakan hamba Allah SWT yang terdiri dari makhluk hidup, di langit dan bumi seperti binatang dan tumbuh-tumbuhan; merupakan salah satu cara kita bersyukur dan memuliakan penciptanya, yaitu Allah SWT. Dapat kita bandingkan bahwa tidak satupun teori pendidikan Barat yang dominan berlandaskan pemikiran Yunani dapat secara spesifik membicarakan dimensi ketuhanan tersebut secara khusus dan mendalam, dan ini secara nyata terekam dalam bait kitab klasik karya Zaini, berupa :

والسماء مخلوق كنملة وما دب على الأرض وما فوق

Tinjauan analisis ilmu pendidikan Barat, senantiasa mendahulukan tinjauan nilai humanis yang muncul secara alami dalam diri tiap manusia, kerap kali tidak membahas pengaruh dari upaya yang muncul hasil dari dimensi vertikal -yaitu hubungan makhluk terhadap tuhannyayang dibangun. Kemudian, sang pengarang memberikan motivasi bagi para pembelajar bahwa implementasi ilmu nanti akan dirasakan oleh masingmasing kita sebagai bentuk timbal balik yang alamiah dari proses panjang yang telah dibangun selama pembelajaran berlangsung. Berikut adalah penggalan bait teks puisinya 
: yang menyatakan hal tersebut

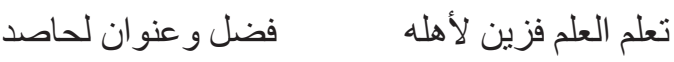

$$
\begin{aligned}
& \text { كلمن مستفيدا كل يوم علما يادة و اصحب أناسا }
\end{aligned}
$$

Ta'allam al-Ilma fa zaynun li ahlihi, fadhlun wa inwanun li hashidin lahu

Kun mstafidan kulla yaumin ilman, ziyadatan wash-hab unasan 'ilman

"Pelajarilah ilmu maka ia akan menghiasimu, engkau akan mendapatkan hasil dari yang telah kamu upayakan. Jadilah manusia yang dapat mengambil manfaat dari ilmu setiap harinya dan terus bertambah, dan berinteraksilah dengan banyak manusia.."

\#qafiyah (rima) yang digunakan dalam 2 (dua) bait di atas adalah harf Hā dan Alif bahs rajaz

Dalam pembahasan khusus yang menjadi ciri khas pada pendidikan Islam adalah peran penting niat seorang pembelajar sebagai tolak ukur keberhasilannya dalam meraih harapan dan cita-cita masa depan. Ini tentu sejalan dengan karakter pembelajaran humanistik yqng merupakan salah satu aliran paedagogi modern; adalah gagasan penting teori belajar yaitu bahwa pembelajar harus mampu mengarahkan dirinya sendiri dalam kegiatan belajar mengajar sehingga mengetahui apa yang dipelajarinya serta tahu seberapa besar siswa tersebut dapat memahaminya. Penafsiran konsep ini merupakan bagian penting dari aplikatif sebuah niat. Seseorang akan termotivasi dan berjuang keras dalam upaya nya meraih mimpi itu karena pijakan niatnya yang sangat kuat. Islam meletakkan niat sebagai dasar evaluasi dari perjalanan para pembelajar, niat bahkan selayaknya harus dievaluasi guna memperbaiki cara pemerolehan yang sebelumnya telah di lakukan. Niat juga menjadi indikasi keberhasilan dan keberkahan dalam ilmu, banyak pembelajar yang dalam kenyataan sepanjang usianya belajar dia tidak mendapatkan hakikatnya ilmu sebagaimana seharusnya. Islam datang dengan kemulyaan, maka hendaknya muslim menjaga kemuliaan iru dengan berupaya meninggalkan kebodohan. Menguatkan diri dan jiwa untuk senantiasa zuhud dan bertakwa kepada allah SWT dalam menghadapi ujian dan cobaan dunia; contohnya seperti menghadang sikap malas yang kerap melanda pada umumnya manusia. Saat kondisi inilah, jihad diri dimotivasi oleh agama melalui teks-teks agama berupa al-qur'an, al-hadis dan pendapat para ulama.

Fondasi ini yang nyatanya juga diperkenalkan, tertata baik dan bahkan berkesinambungan dalam sistem pendidikan Islam beberapa abad silam yang kemudian di adopsi oleh pendidikan Barat juga diresepsi oleh muslim di Nusantara ini melalui produk pemikiran nya. Sebagaimana yang dimaksudkan oleh Zaini dalam penggalan berikut ini :

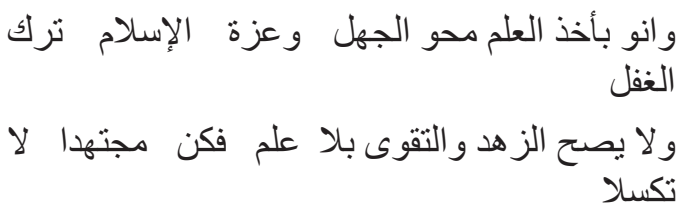

Wanwi bi akhdzi al- 'ilmi mahwa al-jahl, wa 'izzat al-islāmi tarku al-ghafli.

Wa lā yashihhu al-zuhdu wa al-taqwā bi lā 'ilmin, fakun mujtahidan la taksalā

"berniatlah bahwa dengan menuntut ilmu akan menghapus kebodohan, karena kemuliaan Islam adalah dengan meninggalkan kebodohan dalam diri kita. Ilmu adlah syarat utama kita agar dapat bertindak zuhud dan taqwa kepada Allah SWT, maka berusahalah dengan keras..jangan jadi pemalas"

(mir'āt al-afkār:baris 39-40) 
Pendekatan yang juga menarik dalam pembahasan pembelajaran dari teks Zaini ini adalah pola kesabaran yang ditanamkan oleh Islam dalam upaya manusia memperoleh kearifannya melalui belajar, yaitu kesabaran terhadap guru dan buku yang menjadi teman belajar; dengan menyatakan bahwa hendaknya tidaklah menarik diri dari kedua perkara tersebut sekalipun mungkin kita akan menemukan kesulitan dari berinteraksi dengan keduanya. Dan kebenaran hakikat ilmu pun akan didapat dari keduanya pula. Data yang memuat kisi tersebut ada dalam manuskrip ini berupa :

واصبر على الأستاذ والكتاب لا تنتقل بل اتل

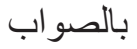

Washbir 'ala al-ustādz wa al-kitāb, lā tantaqilu bal utlu bi al-shawāb

"bersabarlah atas arahan seorang pengajar dan buku, jangan beranjak tergesa-gesa, namun tela'ahlah dengan baik dan benar" (mir'āt al-afkār:baris 75)

Kajian menarik tentang teks ini penetrasi keilmuan bahasa Arab di Nusantara, yaitu tercermin dalam munculnya skrip/aksara Arab fushal formal yang menjadi media tulis Zaini dalam nadzm ini, pembentukan pola rima, irama dan ritme sebuah karya berkarakter puisi, yang terbangun dari proses adopsi cabang keilmuan bahasa Arab yaitu ilmu metrum. Jika kita kaji, manuskrip karya Zaini ini secara jelas menggambarkan tentang nilai pendidikan Islam yang secara jelas mengcover hal mendasar dan lebih spesifik dari kajian aliran pendidikan modern di Barat.

\section{Kesimpulan}

Dari kajian ini, hal penting yang dapat penulis ambil sebagai intisari sebuah penelusuran terhadap data berupa manuskrip yang berjudul "Mir' $\bar{a} \boldsymbol{t}$ Afk $\bar{a} \boldsymbol{r}$ al-Rijäl" adalah bahwa :

Histori yang ada dalam rangkaian produk pemikiran seseorang yang kemudian dituangkan ke dalam bentuk tulisan masa lalu seperti manuskrip merupakan sebuah khazanah ilmu Pengetahuan, tradisi dan budaya yang terekam jelas, sangat berguna untuk memberikan informasi jejak sejarah yang sudah pernah dilalui oleh sebuah komunitas tertentu di sebuah wilayah dalam sebuah negara dan dapat di jadikan sebagai salah satu solusi penyelesaian masa kini dan akan datang dalam bidang yang sama.

Paedagogi Islam yang pondasinya berasal dari konsep al-qur'an dan alhadis, dikembangkan secara luas melalui pemikiran-pemikiran para akademisi muslim dari masa ke masa termasuk di dalamnya adalah di Nusantara, seyogyanya ini tetap menjadi sebuah acuan penting bagi pendidikan kita saat ini khususnya bagi negara mayoritas pemeluk Islam seperti Indonesia.

Teori dan aliran dalam ilmu pendidikan Modern yang marak dibicarakan oleh para ahli pendidikan dan psikologi Barat, adalah sebuah kenyataan untuk kembali memahami konsep pendidikan Islam yang sebelumnya sudah ada dan tersimpan dalam dokumen seperti manuskrip sejak beberapa masa yang lalu. Realitas ini harusnya membawa kita pada referensi klasik yang mengungkap produk pemikiran para cendikia masa lalu yang telah menuliskannya dalam guratan bukti sejarah bernama manuskrip

Pola rima -huruf akhir yang sama antara setengah baris kanan dan setengah baris kiri-, irama -penggalan pola kata yang sesuai dengan penggalan pola kata dalam puisi Arab (taf'ilah), dan ritme - kumpulan penggalan 
pola kata (bahr)- nyata terlihat dalam pembentukan kata dalam kalimat pada nadzm manuskrip Mir'ät Afkār alRijall, adalah bukti adanya penepotret penerapan ilmu metrum Arab ('Arudh wa al-Qawafi) yang diadopsi oleh salah satu cendikia muslim ahmad Zaini asal Solo, Nusantara. Produk pemikiran tentang ilmu paedagogi Islam yang memiliki warna khusus ini, terlihat lebih sempurna dengan digunakannya skrip Arab formal dengan menerapkan pembentukan pola puisi Arab di dalam teks nya.

\section{Daftar Pustaka :}

Al-Qalam, A Iswanto -, and undefined 2016, 'KECENDERUNGAN KAJIAN MANUSKRIP KEISLAMAN DI UIN SYARIF HIDAYATULLAH JAKARTA', Jurnalalqalam.or.Id $\quad<$ http:// jurnalalqalam.or.id/index.php/ Alqalam/article/view/202> [accessed 28 July 2018]

Astuti, Kabul, Aspek Tasawuf Dalam Manuskrip Beraksara Pegon: Kajian Atas Serat Munjiyat Karya Kyai Saleh Darat Dan Singir Parase Nabi Karya Anonim,2014 $<$ http://eprints.ums.ac.id/38306/> [accessed 18 July 2018]

Chinn, Pauline W U, 'Developing Teachers' Place-Based and Culture-Based Pedagogical Content Knowledge and Agency', in Second International Handbook of Science Education (Springer, 2012), pp. 323-34

Ismail, MZ, MK Othman - Jurnal Penyelidikan Dedikasi, and undefined 2018, 'AMALAN PEDAGOGI ABAD KE-21 DALAM KALANGAN GURU PELATIH PROGRAM IJAZAH SARJANA MUDA PERGURUAN
(PISMP) PENDIDIKAN ISLAM DI', Ipgmipoh.Edu.My <http:// www.ipgmipoh.edu.my/journal/ index.php/dedikasi/article/ view/70> [accessed 19 July 2018]

Kanisius, TR, Paradigma
Pedagogi Reflektif, 2010
<https://books.google.com/
books?hl=en\&lr=\&id=DeYO21

